\title{
Elements of a flexible information architecture: A South African perspective
}

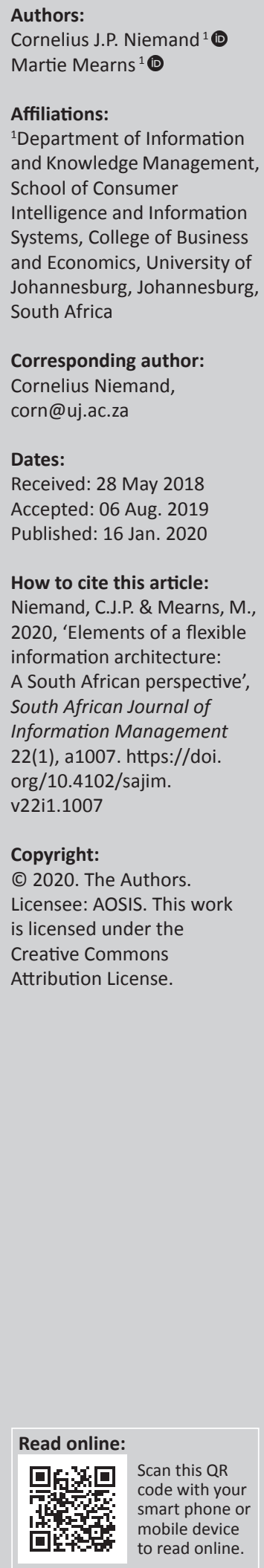

Background: For an organisation to remain competitive, it needs to be aware of, anticipate and adapt to the dynamically changing business environment. Based on the literature study, the research proposes that information and the flexible architecture thereof should be regarded as a core capability of the organisation.

Objectives: The objective of this research article was to identify the elements that are used to measure the effectiveness of an information architecture. The research furthermore postulates that the elements should be utilised as a design approach in the conceptualisation of a flexible alternative information architecture.

Method: A qualitative mono-method research methodology was utilised to investigate which elements are used by experts in the field to measure the effectiveness of information architectures. The Delphi technique was used to collect data from a purposive sample of experts in the field of information architecture.

Results: Based on the literature review and the results of the Delphi technique, the components identified by the expert panel as alternative elements of an information architecture included contextualisation, audit, governance, flexibility and administration.

Conclusion: Considering information architecture as more than just a concept, and extending the notion to a design philosophy, the application and use of the identified elements may contribute to the longevity of the organisation. Thus, the alignment and realignment of the information architectural elements of the organisation will fuel informational flexibility.

Keywords: Information architecture; informational flexibility; dynamically changing business environment; alternative elements of an information architecture; effectiveness of information architectures.

\section{Introduction}

For an organisation to remain competitive, it needs to be aware of, anticipate and adapt to the dynamically changing business environment. Dunford et al. (2013:85) state that because there is the increased tendency to define the organisational environment as being dynamic in nature, flexibility fuelled by information is 'being labelled as a core capability' of the organisation. It should be noted that the concept of flexibility fuelled by information as core capability of the organisation is not new. Koornhof in 1998 hypothesised that the notion of informational flexibility focuses on the implementation of new methods to find, incorporate, process and report on the fundamental economic resource of information. In real terms, this core capability relates 'to the ability of an organisation to quickly and easily implement changes (to adapt) in response to internal or (more often) external impulses' (Matejun 2014:155). Sushil (2015:113-114) extends the notion of the importance of flexibility by adding that flexibility can be 'proactive as well as reactive strategic moves for change'. Sushil (2015:113-114) furthermore suggests that flexibility should be viewed as both internally and externally anchored in the values, culture and competencies of the organisation with specific reference to strategic positioning of the organisation, that is, what makes the organisation unique.

Managers will agree that although the pursuit of flexibility fuelled by information to maintain competitiveness in the market is a priority, modern-day businesses face a multitude of challenges and issues. According to Godinez et al. (2010:5), these challenges may include, but are not limited to, the following:

- The accuracy and timeliness of the information do not support decision-making within the organisational environment. 
- The information environment is usually built in an ad hoc manner, with no central planning about the vision or architecture thereof.

- A multitude of data repositories or warehouses exist within the organisational environment, with limited accountability of role or function thereof.

- There are limited governance and data quality standards that the organisation adheres to.

- The integration of legacy and multiple application systems is expensive, problematic and sometimes impossible to manage.

- In some instances data and technology may be redundant.

- The inability of creating an integrated management information system.

- No cohesion between management and information technology (IT) leadership within the organisational context.

- The inability of the total organisational system to produce valid and reliable analytical data and information.

- IT management is often done in a triage mode and the total cost of ownership is very high.

The underlying themes identified by Godinez et al. (2010:5) are the challenges and issues faced by an organisation relating to business information, how the information flows and how the information is architected within the organisation. In response to the challenges faced, Halter and Ramesh (2016:29) suggest that the next generation of information architectures (IAs) should be:

- 'capability-driven architecture', with information and the analytical analysis of the information at the heart of the organisation

- flexible and hybrid in nature to accommodate any emerging technological advances and changing platforms

- a combination of both open-source and commercial solutions based on the business needs and functionalities

- an architecture that is in line with and based on the operational model of the organisation.

It should be noted that Halter and Ramesh (2016) did not offer any suggestions on what elements, factors or aspects should be considered in designing the next generation flexible and capability-driven IA. Therefore, this research study aims to identify the high-level elements of an alternative flexible IA. The identification of the high-level elements may result in the alignment and realignment of current and future IAs to gain and maintain a competitive advantage.

\section{Literature review}

Information architecture was coined by Richard Saul Wurman in the 1970s during the American Institute of Architects' National Convention in Philadelphia, USA. The initial stance of the definition of IA as suggested by Wurman related more to the visual design of information sources and how to create structures and maps for people to find information, with specific emphasis on the conceptualisation and design of printed media. It should, however, be noted that since the initial conceptualisation of the notion of IA, the importance of the concept within academic discourse and the practical application thereof has become pronounced. The aforesaid concept is based on the work of Evernden and Evernden (2003), who propose that:

\begin{abstract}
... information architecture is a foundation discipline describing the theory, principles, guidelines, standards, conventions and factors for managing information as a resource. It produces drawings, charts, plans, documents, designs, blueprints and templates, helping everyone make efficient, effective, productive and innovative use of all types of information. (p. 1)
\end{abstract}

Building on IA as a theoretical and practical concept, some researchers consider IA as a strategic tool of intent for the organisation. Razak et al. (2008:1011) regard IA as 'a blueprint for how an organization achieves the current and future business objectives ...'. Hinton (2009:47) foresees that ' $[i]$ nformation Architecture is about using information as raw material in the service of architecture for a new contextual reality'.

\section{Information architecture typologies}

Construct development and typology of IA have gone through various iterations. For the purpose of this research study, the work of the four authors mentioned below will be discussed in an attempt to inform and conform to the logical flow and development of the study.

Considering the different viewpoints on the elements constituting an IA, the IA elements according to Brancheau, Schuster and March (1989), Evernden and Evernden (2003), Cormier (2005) and Godinez et al. (2010) are compared. Table 1 represents a summary of the main components of an IA from this comparison. The varying symbols in Table 1 illustrate similarities found in the elements of each of the identified authors' works.

The following inference can be made based on the comparison of the elements of an IA:

- Contextualisation: Information architecture and subsequent information strategy should be based on the organisational intent as described in the business vision, mission and strategy, and a thorough understanding and contextualisation of the business is needed. With reference to the table of comparison of the various elements, the contextualisation concept is evident in the work of Brancheau et al. (1989), the 'understanding element' as defined by Evernden and Evernden (2003) and Cormier's (2005) notion of 'business context', as well as within the 'business context diagram' as proposed by Godinez et al. (2010).

- Understanding: Extending the thought of contextualisation, an understanding of the as-is state of the organisation is needed. If the work of Brancheau et al. (1989) is considered, this perception of understanding is encapsulated by the concepts of 'information requirements' and 'information resources'. Evernden and Evernden (2003) are of the opinion that to understand means to be able to define and explain the context of the information within the predefined boundaries of the organisational environment. Thus, for 
TABLE 1: Comparison of the elements of an information architecture.

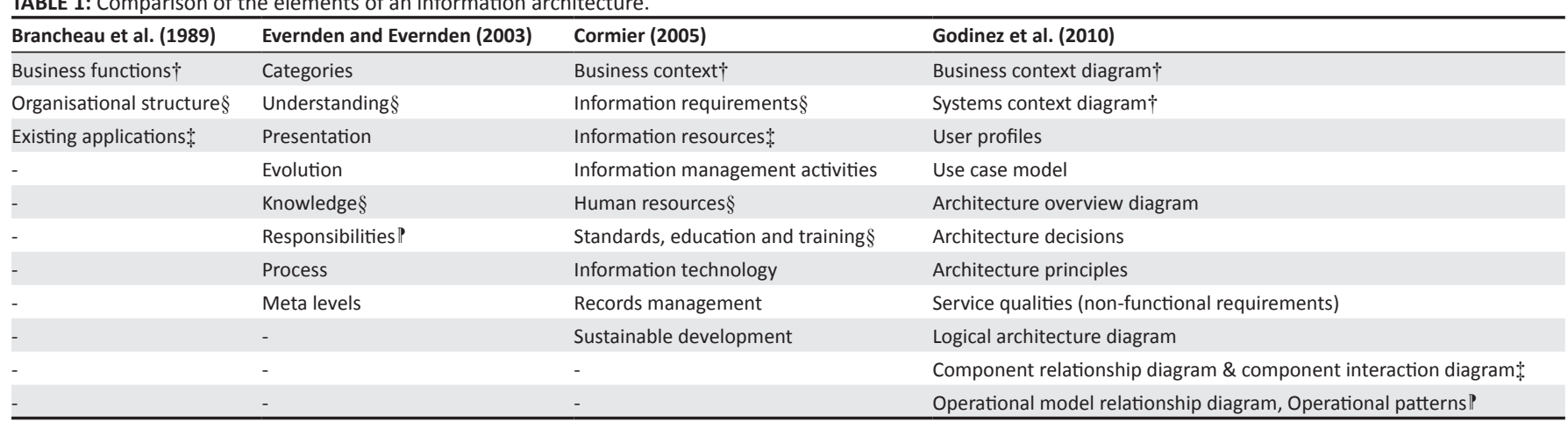

Note: The symbols $(\uparrow, \$, \S, \mathbb{P})$ denotes similarities in concept between the authors work.

the purpose of the current study and extending the previous statement by Evernden and Evernden (2003), the most applicable tool to understand, is to apply an audit. The audit element incorporates the elements of what requirements are necessary, what resources are needed, what activities and responsibilities should be identified and allocated in the architecting of the information in the organisational context.

- Governance: As indicated in the comparison table, Evernden and Evernden (2003), Cormier (2005) and Godinez et al. (2010) identify some basic elements of adhering to internal or external rules, including but not limited to responsibilities, standards and principles.

- Administrative activities: The importance of the administrative side of IA is highlighted by Godinez et al. (2010). Various elements of administrative activities are encapsulated by the 'work products' as defined by Godinez et al. (2010). These activities include diagrams illustrating relationships and components of the IA.

- Flexibility: Although not explicitly stated, all the authors identified inferred to the fact that the activity of architecting information within the organisational context should be regarded as a continuous process and not an end-state. The inferred notion is extended and reiterated by Halter and Ramesh (2016:29), who stated that future developments in IAs should be flexible and hybrid in nature to accommodate and mitigate any changes in the organisational environment.

The similarities and results of the comparison of the works of Brancheau et al. (1989), Evernden and Evernden (2003), Cormier (2005) and Godinez et al. (2010) are visually presented in Figure 1.

The literature review, culminating in the identified elements of an IA as shown in Figure 1, will form the basis of the identification of the elements needed for the structuring of an organisation operating in an information economy.

\section{Methodology}

This article forms part of a series of papers, based on the findings of an unpublished $\mathrm{PhD}$ investigating the use of information audits methodologies to ascertain the effectiveness of IAs. The rationale of the focus of this

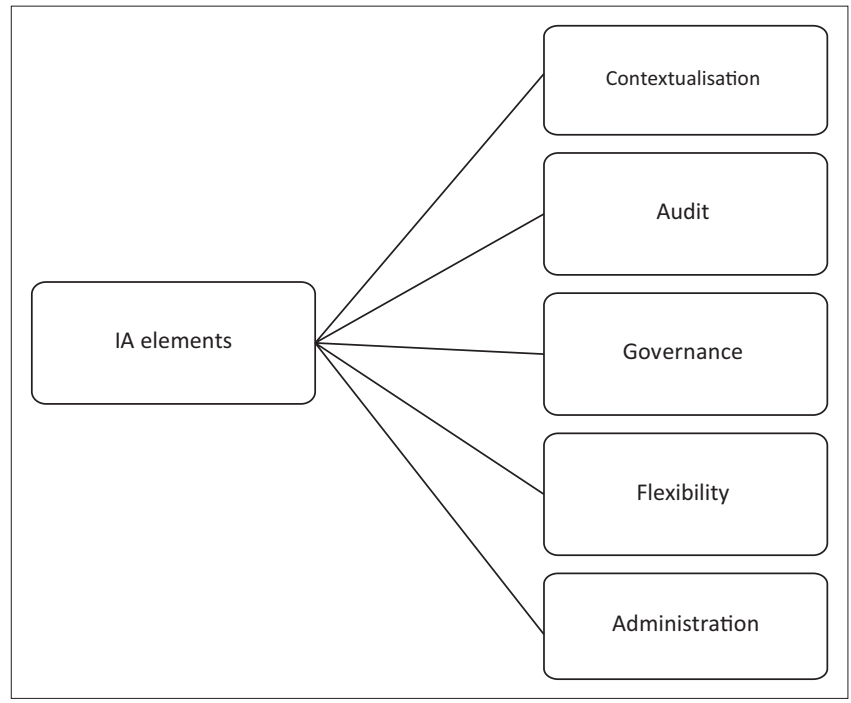

IA, information architecture.

FIGURE 1: Architectural elements of an information architecture.

research article is based on the work of Dillon and Turnbull (2006:4), who are of the opinion that the term 'information architecture' should not only be seen as defining a concept, but can also be used to describe a design approach, that is, 'the design with specific methodologies for managing the deployment of resources and sequencing of deliverables'. Thus, by identifying the elements to measure the effectiveness of an IA, an alternative architecture may be conseptualised based on the identified elements. To this end, the formal research question may be conceptualised as follows: which measuring elements should be included in a matrix for measuring the effectiveness of an information architecture?

Based on Hauer and Muntean (2010:3), the ontological stance employed by the current study concurs with and will represent the existence of multiple realities which when subjectively interpreted will result in a social construct. Extending the ontological stance of the study, neopragmatism is identified as the specific ontological stance for the study. The aforesaid stance is based on the notion proposed by Jacobs (2010:725), who summarises the neopragmatist approach simply by stating that the 'methodology embraces trial and error'. Sekaran and Bougie (2013:30) extend the viewpoint of Jacobs (2010:725) and add that the 
'[neo]-pragmatists do not take on a particular position on what makes good research'. Thus, the neo-pragmatic researcher is of the opinion that both observable, real-life phenomena and subjective research can produce and contribute towards the body of knowledge under investigation.

The epistemological assumption for the study is based on the insights of one of the most influential protagonists of pragmatism, Charles Sanders Peirce. According to Jacobs (2010:725), Peirce 'argued for abduction' as an epistemological assumption. Saunders, Lewis and Thornhill (2012:147) describe abductive reasoning as 'the observation of a "surprising fact"; it then works out a plausible theory of how this could have occurred'. Reichertz (2014:126), is of the opinion that the feeling of doubt may be regarded as the catalyst for inquiry and that genuine doubt drives the research process and activity.

Extending the ontological and epistemological stance of the study, a qualitative research methodology was employed to investigate how experts in the field experience the reality of measuring the effectiveness of an IA by means of information audit methodologies. The Delphi technique, which was originally developed to predict future events as well as the outcomes of the events, based on the inputs from and the circumstances present in the environment, was used to collect data. Thangaratinam and Redman (2005), is of the opinion that 'a suitable minimum panel size [for the application of the Delphi technique] is seven'. Hsu and Sandford (2012) are of the opinion that the number of contributors in a Delphi technique is generally between 15 and 20 experts in the field of research. The authors considered the opinion of Hsu and Sandford (2012) and implemented the suggested 15-20 experts as the sample size for this research.

A purposive sampling technique was used in this study through contact details from a LinkedIn group (South African Enterprise Information Architecture Group) to identify and request participation in the research. LinkedIn and the LinkedIn group were purposively chosen based on the notion that the participants identified will have professional yet practical skills and knowledge pertaining to the topic at hand. The Massachusetts Institute of Technology (MIT) Architecture Position Description report was used to identify specific criteria for the participants of the Delphi technique. The inclusion criteia for participation were as follows: the participants must be willing, able and have time to participate in the research. The participants should be associated with, employed by or participate in a South Africa-based organisation. Furthermore, the participants should exhibit basic managerial characteristics including consulting and change management skills. The most important consideration to qualify is sufficient expertise in the field of IA.

\section{Reporting on the Delphi technique}

The visual representations (see Figure 2) detail the manner in which the Delphi process was managed. It also reports on the attrition of experts experienced during data collection and analysis stages of the Delphi process.

Round 1 applied the method of analysis in the open-ended answers according to thematic classification. This formed the basis of the review questions for the consensus-seeking questionnaire used in Round 2. In Round 2, two experts withdrew from the study, thus affecting analysis of the level of agreement to develop the opportunity to verify and validate the expert's level of agreement or disagreement towards the consensus-seeking questionnaires. Four experts withdrew from the study in Round 3. Revision and reformulation of the statements followed. During consensus seeking in Round 4, all originally sampled experts agreed to the newly revised statements and no further revisions were recommended as the consensus was achieved.

\section{Ethical consideration}

This article followed the ethical process outlined by the University of Johannesburg.

\section{Results}

Considering the literature review and extending on the work of Brancheau et al. (1989), Evernden and Evernden (2003),

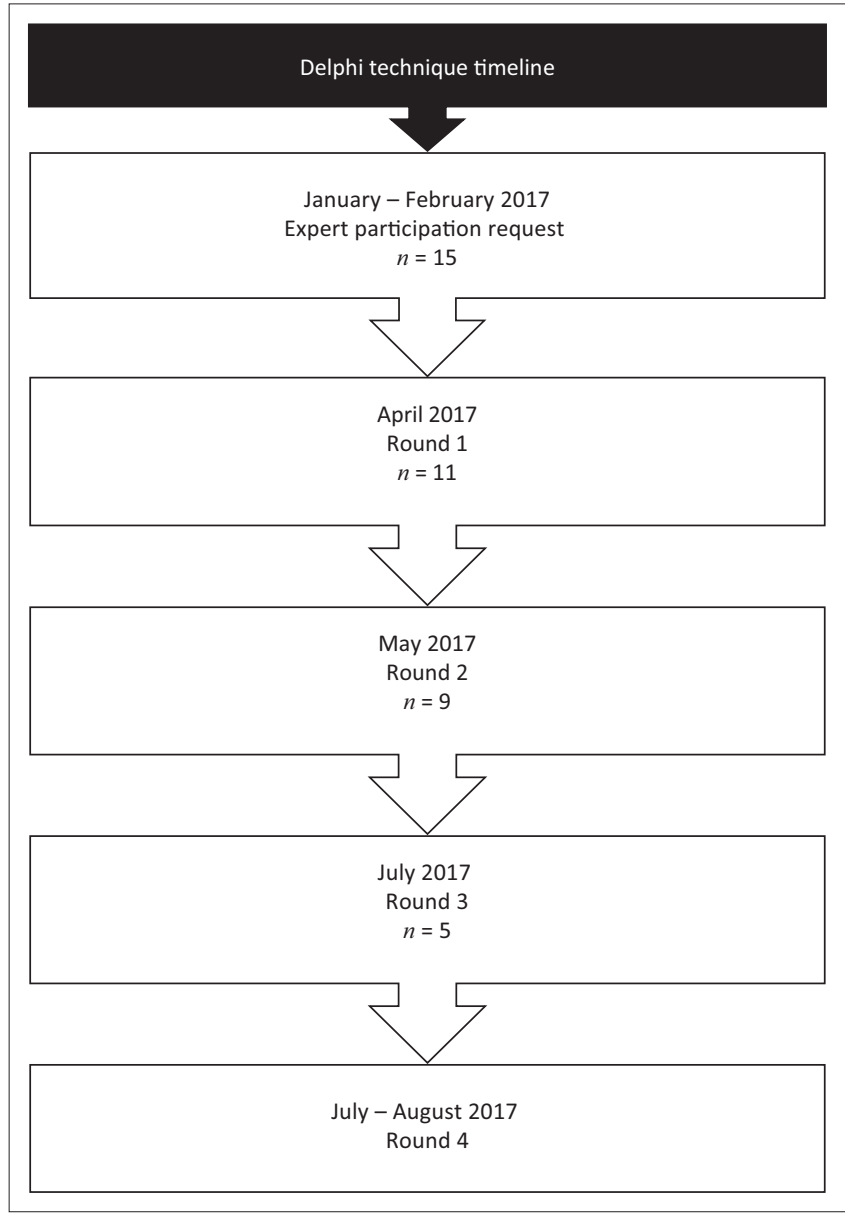

FIGURE 2: Delphi technique timeline. 
Cormier (2005) and Godinez et al. (2010), the expert panel of IA specialists was presented with the new alternative elements of an IA, as shown in Figure 3. The panel was asked to share its opinion and thoughts on the sub-elements within the boundaries of the Delphi technique.

Various responses and sub-elements were captured from the expert panel, relating to the presentation of the elements that should be included in an IA operating in the current economic climate. Applying thematic analysis, the sub-elements were grouped according to specific themes.

In considering the statements and sub-elements as identified in the first round of the Delphi technique, the expert panel was requested to indicate their level of agreement, neutrality or disagreement pertaining to each of the sub-elements of the proposed alternative IA. The results of the second round of the Delphi technique are presented in Table 2.

In order to explain and rationalise the results in Table 2, it should be noted that verbatim quotes received from the respondents were referenced based on a coding convention. This coding convention includes the panel member number and the specific round within which the verbatim quote was captured; for example, if panel member 1 stated an important concept during Round 2 of the Delphi technique, then the coding convention used to reference the quote was PM1R2.

Table 3 provides an overview of the verbatim quotes of the panel members pertaining to possible reasons why they neither agreed nor disagreed or totally disagreed with a particular element being included in the IA.

It should be noted that the results of Round 3 of the Delphi technique were communicated and that the panel of experts did not make any changes or suggestions towards any changes in terms of the elements that should form part of the alternative IA. During Round 4 all experts agreed to the alternative IA elements and no further revisions were recommended.

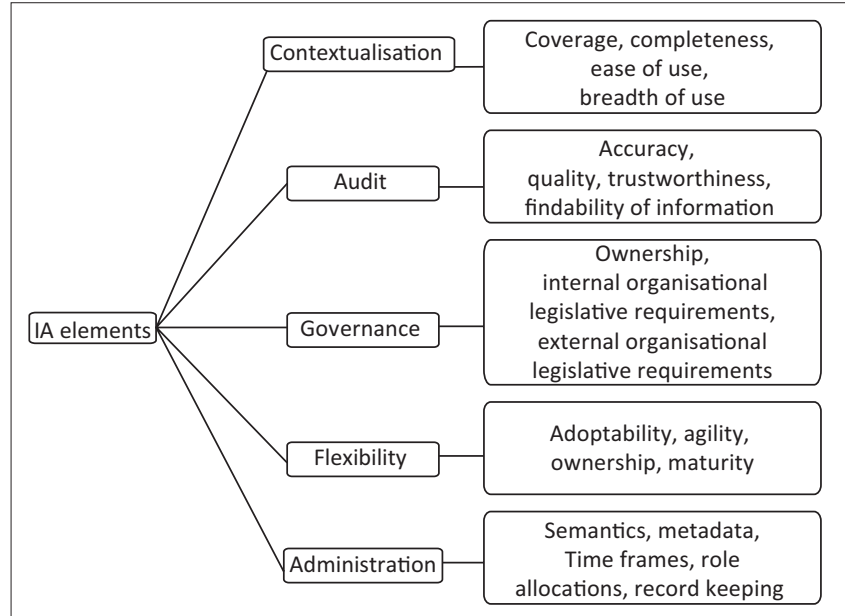

IA, information architecture.

FIGURE 3: Alternative architectural elements of an information architecture.

\section{Analysis}

Considering the results obtained from the Delphi technique and to ensure sound academic discourse, each of the identified elements needs to be analysed and justified.

\section{Contextualisation}

The elements that constituted the concept of contextualisation included coverage, completeness, ease of use and breadth of use. The rationale and justification of the elements contributing to the contextualisation of the measuring elements relate to the fact that the elements should cover and represent the complete information environment of the organisation. Furthermore, the measuring elements should be easy to use in a multitude of different business environments. Contextualisation within the parameters of the current study and that of the Delphi technique considers the strategic intent of the organisation as a departure point in terms of contextualisation. Therefore, contextualisation is the 'understanding element' as defined by Evernden and Evernden (2003), Cormier's (2005) notion of 'business context' and Godinez et al.'s (2010) articulation of a 'business context diagram'.

\section{Audit}

The elements of accuracy, quality, trustworthiness and findability can be grouped under the theme of audit. If the thematical description of an audit is considered, that is, if it

TABLE 2: Level of consensus pertaining to the components of the alternative architectural elements of an information architecture.

\begin{tabular}{|c|c|c|c|}
\hline \multirow{2}{*}{$\begin{array}{l}\text { Statement from Round } 1 \\
(n=11)\end{array}$} & \multicolumn{3}{|c|}{ Consensus Round $2(\%, n=9)$} \\
\hline & $\begin{array}{l}\text { Totally } \\
\text { agree }\end{array}$ & $\begin{array}{l}\text { Neither agree } \\
\text { nor disagree }\end{array}$ & $\begin{array}{c}\text { Totally } \\
\text { disagree }\end{array}$ \\
\hline \multicolumn{4}{|l|}{ Contextualisation } \\
\hline Coverage & 100 & 0 & 0 \\
\hline Completeness & 89 & 11 & 0 \\
\hline Ease of use & 56 & 44 & 0 \\
\hline Breadth of use & 67 & 33 & 0 \\
\hline \multicolumn{4}{|l|}{ Audit } \\
\hline Accuracy & 89 & 11 & 0 \\
\hline Quality & 89 & 11 & 0 \\
\hline Trustworthiness & 67 & 33 & 0 \\
\hline Findability of the information & 56 & 33 & 11 \\
\hline \multicolumn{4}{|l|}{ Governance } \\
\hline Ownership & 89 & 11 & 0 \\
\hline $\begin{array}{l}\text { Internal organisational legislative } \\
\text { requirements }\end{array}$ & 67 & 33 & 0 \\
\hline $\begin{array}{l}\text { External business and } \\
\text { environmental legislative } \\
\text { requirements }\end{array}$ & 67 & 33 & 0 \\
\hline \multicolumn{4}{|l|}{ Flexibility } \\
\hline Adoptability & 67 & 33 & 0 \\
\hline Agility & 78 & 22 & 0 \\
\hline Ownership & 44 & 56 & 0 \\
\hline Maturity & 45 & 44 & 11 \\
\hline \multicolumn{4}{|l|}{ Administration } \\
\hline Semantics & 56 & 44 & 0 \\
\hline Metadata & 89 & 11 & 0 \\
\hline Time frames & 33 & 56 & 11 \\
\hline Role allocations & 67 & 33 & 0 \\
\hline Record keeping & 56 & 44 & 0 \\
\hline
\end{tabular}


TABLE 3: Verbatim quotes pertaining to proposed architectural elements.

\section{Original statement: Round $1(n=11)$}

\section{Contextualisation}

- The elements that should be included in a matrix for measuring the effectiveness of an information architecture can be clustered according to some other themes. Why do you neither agree nor disagree with 'ease of use' as an element?

- The elements that should be included in a matrix for measuring the effectiveness of an information architecture can be clustered according to themes. Why do you neither agree nor disagree with 'breadth of use' as an element?

\section{Audit}

- The elements that should be included in a matrix for measuring the effectiveness of an information architecture can be clustered according to themes. Why do you neither agree nor disagree with 'trustworthiness' as an element?

- The elements that should be included in a matrix for measuring the effectiveness of an information architecture can be clustered according to themes. Why do you neither agree nor disagree with 'findability of the information' as an element?

\section{Governance}

- The elements that should be included in a matrix for measuring the effectiveness of an information architecture can be clustered according to themes. Why do you neither agree nor disagree with 'ownership' as an element?

- The elements that should be included in a matrix for measuring the effectiveness of an information architecture can be clustered according to themes. Why do you neither agree nor disagree with 'internal organisational legislative requirements' as an element?

- The elements that should be included in a matrix for measuring the effectiveness of an information architecture can be clustered according to themes. Why do you neither agree nor disagree with 'external business and environmental legislative requirements' as an element?

\section{Flexibility}

- The elements that should be included in a matrix for measuring the effectiveness of an information architecture can be clustered according to themes. Why do you neither agree nor disagree with 'adoptability' as an element?

- The elements that should be included in a matrix for measuring the effectiveness of an information architecture can be clustered according to themes. Why do you neither agree nor disagree with 'agility' as an element?

- The elements that should be included in a matrix for measuring the effectiveness of an information architecture can be clustered according to themes. Why do you neither agree nor disagree with 'ownership' as an element?

- The elements that should be included in a matrix for measuring the effectiveness of an information architecture can be clustered according to the themes. Why should 'maturity' be excluded from the elements?

- The elements that should be included in a matrix for measuring the effectiveness of an information architecture can be clustered according to the themes. Why should 'maturity' be excluded from the elements?

Verbatim quote: Round $3(n=5)$

- PM6R3: 'In order to group logical themes together - to understand the interconnectedness of the themes - where appropriate'.

- PM8R3: 'From a contextual viewpoint, you're measuring the scope, breadth and depth, which might not entirely include the ease of use'.

- PM9R3: "Ease of use" is a very personal measurement. It depends totally on the user and the skills of the user. But I also like to include it - then it reflects my preference'.

- PM6R3: 'Same as above'. - 'In order to group logical themes together - to understand the interconnectedness of the themes - where appropriate'.

- PM9R3: 'Because I do not understand what you will be measuring'.

- PM8R3: 'Trustworthiness is subjective, and although it can constitute a measuring element, the accuracy of the data may be questionable'.

- PM2R3: 'I cannot recall the reason'.

- PM6R3: 'Same as above. In order to group logical themes together - to understand the interconnectedness of the themes - where appropriate'.

- PM8R3: 'Like trustworthiness, findability is subjective and although it can constitute a measuring element, the accuracy of the data may be brought into question'.

- PM2R3: 'I don't understand how ownership is associated with the theme governance'

- PM8R3: 'While ownership is a vital aspect of governance, internal organizational [sic] legislative requirements might be useful measuring elements, but not vital in my view'.

- PM8R3: 'Likewise, external business and environmental legislative requirements might add useful data, it's not vital in my opinion'.

- PM6R3: 'Same as above. In order to group logical themes together - to understand the interconnectedness of the themes - where appropriate'.

PM8R3: 'Adoptability may yield valuable data, but I am of the view that it is out of place in the "flexibility" theme'.

- PM6R3: 'Same as above. In order to group logical themes together - to understand the interconnectedness of the themes - where appropriate'.

- PM9R3: 'I do not believe that all parts of your IA should be very agile and changing too often. Some parts might be agile'.

- PM8R3: 'Ownership may yield valuable data, but I am of the view that it is out of place in the "flexibility" theme'

- PM2R3: 'Maturity has nothing to do with the theme under which it is grouped'.

- PM6R3: 'Same as above. In order to group logical themes together - to understand the interconnectedness of the themes - where appropriate'.

PM8R3: 'Maturity may yield valuable data, but I am of the view that it is out of place in PM8R3: "Maturity may
the "flexibility" theme'.

is considered as a formal, replicable and structured process, all the elements grouped justify, explain and measure the process and activity of the IA. The works of Brancheau et al. (1989) and Evernden and Evernden (2003) form the basis of the justification for the inclusion of the concept 'understanding' as an alternative element in the IA. If the thematic analyses of the statements are considered, the current study proposes that the elements of understanding should be grouped under the 'audit' theme, that is, they should define and explain the context of the information within the predefined boundaries of the organisational environment.

\section{Governance}

Several of the expert panel members identified elements of internal and external legislative aspects that should form part of the elements of an IA. In real terms, the governing function and activity should also be assigned to a specific individual, group or entity within the larger context of the group or organisation. The inclusion of the concept of governance is justified based on the works of Evernden and Evernden (2003), Cormier (2005) and Godinez et al. (2010), who indicated that all IA models and methodologies should adhere to some basic elements of internal as well as external rules governing the process.

\section{Flexibility}

The elements assigned to the theme of flexibility included adoptability, agility, ownership and maturity. These elements were grouped accordingly to ensure that the measuring tool as well as activity is flexible in its micro- and macro-business environment, in its application and context. The need for the inclusion of the concept of flexibility within the conceptual matrix may be warranted by means of the acknowledgement of the hypothesis of Halter and Ramesh (2016:29). The authors suggest the need for a 'capability-driven architecture' that is flexible and hybrid to facilitate and accommodate the changing business environment. Although various points of view have been observed in the responses of the expert panel, the consensus reached in Round 4 of the Delphi technique 
illustrates the importance of accepting some level of flexibility within the construct of an IA.

\section{Administration}

According to the expert panel, some level of administrative functions and activities should have been included as part of the elements of an IA. The theme of administration included elements relating to the semantics used within the organisational context, a description and list of metadata elements, associated time frames for the evaluation of the IA, the allocation of roles and responsibilities and, finally, keeping an auditable trail of all the elements of the evaluation activities and functions. Because of the importance of information and the architecting of information within the organisational context, the management activity thereof is self-explanatory. Theneed for an administrative concept to be included in the conceptual matrix is justified by Godinez et al. (2010), who grouped the administrative activities in specific work products to be managed by the executives of the function and organisation.

Based on the fact that Halter and Ramesh (2016) did not offer any suggestions on what elements should be considered in designing the next generation IA, the importance of the identification and delineation of the elements as discussed in this section is self-evident. The elements can thus be considered as tools and a measuring instrument to align and realign the IA of an organisation to mitigate the ever-changing business environment.

\section{Conclusion}

In considering Dillon and Turnbull (2006:4), who stated that IA should not only be seen as a concept but can also be used to describe a design approach, that is, 'the design with specific methodologies for managing the deployment of resources and sequencing of deliverables', elements that will assist in the architecture of an alternative information reality for an organisation were identified. The elements proposed for inclusion in an alternative IA include the contextualisation, audit, governance, flexibility and administration. By utilising the said elements, the notion of informational flexibility as suggested by Koornhof in 1998, who hypothesised that within the boundaries of the current economic climate the focus of an organisation should be on the implementation of new methods to find, incorporate, process and report on the fundamental economic resource of information, will be realised. The elements identified in this study form the base elements of a larger study, which aims to conceptualise a matrix to measure the effectiveness of IAs.

\section{Acknowledgements Competing interests}

The authors have declared that no competing interests exist.

\section{Authors' contributions}

Both authors contributed equally towards the research and the article writing.

\section{Funding information}

This research received no specific grant from any funding agency in the public, commercial or not-for-profit sectors.

\section{Data availability statement}

Data sharing is not applicable to this article as no new data were created or analysed in this study.

\section{Disclaimer}

The views and opinions expressed in this article are those of the authors and do not necessarily reflect the official policy or position of any affiliated agency of the authors.

\section{References}

Brancheau, J.C., Schuster, L. \& March, S.T., 1989, 'Building and implementing an information architecture', ACM SIGMIS Database 20(2), 9-17. https://doi. org/10.1145/1017914.1017916

Cormier, P., 2005, 'The way ahead for information management', Canadian Military Journal, Autumn, 43-48.

Dillon, A. \& Turnbull, D., 2006, Information architecture, viewed 25 August 2017, from http://donturn.com/tag/information-architecture/.

Dunford, R., Cuganesan, S., Grant, D., Palmer, I., Beaumont, R. \& Steele, C., 2013, '"Flexibility" as the rationale for organisational change: A discourse perspective', Journal of Organisational Change Management 26(1), 83-97. https://doi. org/10.1108/09534811311307923

Evernden, R. \& Evernden, E., 2003, Information first: Integrating knowledge and information architecture for business advantage, Elsevier Butterworth Heinemann, Oxford.

Godinez, M., Hechler, E., Koenig, K., Lockwood, S., Oberhofer, M. \& Schroeck, M., 2010, The art of enterprise information architecture: A systems-based approach for unlocking business insight, IBM Press, Upper Saddle River, NJ.

Halter, O. \& Ramesh, R., 2016, 'Ushering in the next generation of information architecture', Business Intelligence Journal 20(4), 28-38.

Hauer, I. \& Muntean, C., 2010, 'An overview of ontologies and knowledge management', Lucrari Stiintifice Seria I, Management Agricol 12(2), 1-8.

Hinton, A., 2009, 'The machineries of context. New architectures for a new dimension', Journal of Information Architecture 1(1), 37-47.

Hsu, C.-C. \& Sandford, B.A., 2012, 'Delphi technique', in N.J. Salkin (ed.), Encyclopedia of research design, Sage, n.p. https://doi.org/10.4135/9781412961288

Jacobs, D.C., 2010, 'Pragmatism', in A.J. Mills, G. Durepos \& E. Wiebe (eds.), Encyclopaedia of case study research, Sage, n.p. https://doi.org/10.4135/ 9781412957397

Koornhof, C., 1998, 'Accounting information on flexibility', Unpublished doctoral thesis, University of Pretoria, Pretoria.

Matejun, M., 2014, 'The role of flexibility in building the competitiveness of small and medium enterprises', Management 18(1), 154-168. https://doi.org/10.2478/ manment-2014-0012

Razak, R.A., Dahalin, Z.M., Dahari, R., Kamaruddin, S.S. \& Abdullah, S., 2008, 'Evaluation of Enterprise Information Architecture (EIA) practices in Malaysia', in L.D. Xu, A.M. Tjoa \& S.S. Chaudhry (eds.), Research and practical issues of enterprise information systems II. IFIP International Federation for Information Processing, vol. 255, pp. 1011-1017, Springer, Boston, MA.

Reichertz, J., 2014, 'Induction, deduction, abduction', in U. Flick (ed.), The Sage handbook of qualitative data analysis, Sage, n.p. https://doi.org/10.4135/ 9781446282243

Saunders, M., Lewis, P. \& Thornhill, A., 2012, Research methods for business students, 6 th edn., Prentice Hall, London.

Sekaran, U. \& Bougie, R., 2013, Research methods for business: A skill-building approach, 6th edn., John Wiley, London.

Sushil, 2015, 'Strategic flexibility: The evolving paradigm of strategic management', Global Journal of Flexible Systems Management 16(2), 113-114. https://doi. org/10.1007/s40171-015-0095-z

Thangaratinam, S. \& Redman, C.W.E., 2005, 'The Delphi technique', The Obstetrician \& Gynaecologist 7(2), 120-125. 